\title{
MicroRNA-381 protects myocardial cell function in children and mice with viral myocarditis via targeting cyclooxygenase- 2 expression
}

\author{
YONG ZHANG $^{1 *}$, LINGLI SUN $^{1 *}$, HUI SUN ${ }^{2}$, ZHONGQIN YU ${ }^{2}$, XIALIU $^{2}$, \\ XIA LUO ${ }^{2}$, CUIFANG LI ${ }^{2}$, DONGMING SUN ${ }^{1}$ and TAO LI ${ }^{2}$ \\ ${ }^{1}$ Cardiology Department, Wuhan Children's Hospital, Tongji Medical College, Huazhong \\ University of Science and Technology, Wuhan, Hubei $430015 ;{ }^{2}$ Department of Pediatrics, \\ Taihe Hospital, Hubei University of Medicine, Shiyan, Hubei 442000, P.R. China
}

Received August 19, 2017; Accepted January 16, 2018

DOI: $10.3892 /$ etm.2018.6082

\begin{abstract}
The present study aimed to determine the expression of cyclooxygenase (COX)-2 and microRNA (miRNA/miR)-381 in the blood of children with viral myocarditis (VM), and investigate the association between COX-2 and miR-381 in the occurrence and development of the disease using a mouse model. A total of 26 children with VM (15 boys and 11 girls) were included in the present study. Peripheral blood was collected from all children. The mouse model of VM was constructed by coxsackievirus B3 (CVB3) infection. Peripheral blood and myocardial tissues were collected from all mice for analysis. Reverse transcription-quantitative polymerase chain reaction was used to determine the expression of COX-2 mRNA and miR-381 in serum and myocardial tissues. ELISA was used to measure the content of COX-2 protein in serum from humans and mice, and western blotting was employed to determine the expression of COX-2 protein in myocardial tissues from mice. Contents of creatine kinase (CK-MB) and lactate dehydrogenase (LDH) were evaluated using an automatic biochemical analyzer. A dual luciferase assay was conducted to identify interactions between COX-2 mRNA and miR-381. Children with VM had increased COX-2 levels and decreased miR-381 expression in peripheral blood, compared with those who had recovered from VM. CVB3 infection resulted in damage in the myocardium of mice, and elevated CK-MB and LDH contents. VM model mice exhibited increased COX-2 levels and decreased miR-381 expression in peripheral blood and myocardial tissues compared with normal mice. miR-381
\end{abstract}

Correspondence to: Dr Tao Li, Department of Pediatrics, Taihe Hospital, Hubei University of Medicine, 32 People's South Road, Shiyan, Hubei 442000, P.R. China

E-mail: taoLi0311@163.com

${ }^{*}$ Contributed equally

Key words: viral myocarditis, cyclooxygenase-2, miR-381 binds to the 3'-untranslated seed regions of both human and mouse COX-2 mRNA to regulate their expression. The present study demonstrated that children with VM have decreased miR-381 expression and elevated COX-2 expression in peripheral blood. miR-381 may inhibit myocardial cell damage caused by CVB3 infection and protect myocardial cell function by targeting COX-2 expression.

\section{Introduction}

The incidence of viral myocarditis (VM) is gradually increased in recent years, and attracts the attention of more and more scholars (1). Coxsackievirus B3 (CVB3) is one of the most common viruses that cause VM (2). VM can develop into acute heart failure $(3,4)$. According to available clinical studies, the mortality rate of VM in young people is as high as $21 \%$, and sudden deaths caused by VM or fatal ventricular arrhythmias in children account for about $20 \%(5,6)$. However, there have been few effective therapies for VM by now. Current treatment for VM is still focused on the control of cardiac arrhythmia and heart failure. Therefore, it is necessary to study the molecular mechanism of VM.

VM is a common infectious disease in pediatric clinical practice. It is caused by viral infection or disturbance of autoimmune system, and characterized by localized or diffuse acute or chronic inflammatory lesions of the myocardium (1,7). In inflammation, cyclooxygenase (COX), especially COX-2 in the COX family, plays an important role. COX-2 is produced after induction by external stimuli (physical, chemical, biological, etc), and catalyzes the synthesis of prostaglandin that is involved in inflammatory responses (8). With the study on genes entering microRNA (miRNA/miR) stage, some researchers have found that up-regulation of miRNAs can inhibit the expression of COX-2 (9). However, basic and clinical research processes of $\mathrm{VM}$ and the regulation of COX-2 by miRNAs are rarely reported. In the present study, we determine the expression of COX-2 in the blood of children with VM, and investigate the relationship between COX-2 and miR-381 in the occurrence and development of the disease. 


\section{Materials and methods}

Patients. A total of 26 children with VM (15 boys and 11 girls) admitted at our hospital between June 2014 and February 2017 were included in the present study. The age range of the children was from 9 months to 16 years. Clinical diagnosis was made according to the standards of VM established by the cardiovascular research group of Chinese Medical Association in 2000 (10). All children with VM received large doses of vitamin C, protection of important organ functions, symptomatic treatments, myocardial nutrition, and anti-virus treatment. Control group (33 children) included children with VM who required regular follow-ups after recovery. Three types of samples were collected and used in the experiments. Peripheral blood was collected from all patient children and those in control group at early morning fasting, and stored at $-20^{\circ} \mathrm{C}$ in EDTA anti-coagulant tubes. All procedures were approved by the Ethics Committee of Hubei University of Medicine. Written informed consents were obtained from all patients or their families.

Animals. A total of 60 male BALB/C mice (4 weeks old) were obtained from Chongqing Tengxin Biotech Company (http://www.cqtx123.com/; Chongqing, China) with a certificate numbered SCXK(Yu) 2016-0018. The weight of the mice ranged between 18 and $22 \mathrm{~g}$. During the week before experiments, the mice had free access to food and water to adapt to the environment. The Reduction, Replacement and Refinement animal welfare principle was followed during the experiments. The mice were divided into control group and infection (VM) group. Control group ( $\mathrm{n}=30$ ) was not infected by any virus and intraperitoneally injected with saline $(0.2 \mathrm{ml})$. VM group $(\mathrm{n}=30)$ was intraperitoneally injected with 100 TCID50 CVB3 (0.2 ml; Biopike, Beijing, China), and one hour later, the mice were injected with saline $(0.2 \mathrm{ml})$. The mice in $\mathrm{VM}$ group were treated with CVB3 for three days, and sacrificed on day 21. Peripheral blood was collected from the mice, and stored at $-20^{\circ} \mathrm{C}$ in EDTA anti-coagulant tubes. Then, myocardial tissues were collected after the mice were sacrificed by decapitation, and stored in liquid nitrogen.

Reverse transcription-quantitative polymerase chain reaction $(R T-q P C R)$. Myocardial tissues $(100 \mathrm{mg}$ ) were ground using liquid nitrogen and mixed with $1 \mathrm{ml}$ TRIzol (10606ES60; Yeasen, Shanghai, China) for lysis. Serum samples $(100 \mu \mathrm{l})$ were directly mixed with $1 \mathrm{ml}$ TRIzol (10606ES60; Yeasen, Shanghai, China) for lysis. Then, total RNA was extracted using phenol chloroform method. The concentration and quality of RNA was examined using ultraviolet spectrophotometry (Nanodrop ND2000; Thermo Fisher Scientific, Inc., Wilmington, DE, USA). Then, cDNA was obtained by reverse transcription from $1 \mu \mathrm{g}$ RNA and stored at $-20^{\circ} \mathrm{C}$. Reverse transcription of mRNA was performed using TIANScript II cDNA First Strand Synthesis kit (KR107; Tiangen, Beijing, China), and reverse transcription of miRNA was carried out using miRcute miRNA cDNA First Strand Synthesis Kit (KR201; Tiangen).

SuperReal PreMix (SYBR-Green) RT-qPCR kit (FP204; Tiangen) was used to detect mRNA expression of COX-2, using $\beta$-actin as internal reference. The sequences of human COX-2 were 5'-CAGCCATACAGCAAATCCTTG-3' (upstream) and 5'-CAAATGTGATCTGGATGTCAAC-3' (downstream), and those of $\beta$-actin were 5'-CACCAGGGCGTGATGGT-3' (upstream) and 5'-CTCAAACATGATCTGGGTCAT-3' (downstream). PCR reaction system (20 $\mu \mathrm{l})$ for human COX-2 determination was composed of $10 \mu \mathrm{l}$ RT-qPCR-Mix, $0.5 \mu \mathrm{l}$ upstream primer, $0.5 \mu 1$ downstream primer, $2 \mu \mathrm{l}$ cDNA and $7 \mu \mathrm{lddH_{2 }}$ O. PCR conditions for human COX-2 determination were: Initial denaturation at $95^{\circ} \mathrm{C}$ for $30 \mathrm{sec} ; 40$ cycles of $95^{\circ} \mathrm{C}$ denaturation for $5 \mathrm{sec}$ and annealing at $60^{\circ} \mathrm{C}$ for $34 \mathrm{sec}$ (iQ5; Bio-Rad Laboratories, Inc., Hercules, CA, USA). The sequences of mouse COX-2 were 5'-CAGCAAATCCTT GCTGTTCC-3' (upstream) and 5'-TGGGCAAAGAAT GCAAACATC-3' (downstream), and those of $\beta$-actin were 5'-TCAGGAGGAGCAATGATCTTG-3' (upstream) and 5'-TCC TCCCTGGAGAAGAGCTA-3' (downstream). PCR reaction system $(20 \mu \mathrm{l})$ for mouse COX-2 determination was composed of $10 \mu \mathrm{l}$ RT-qPCR-Mix, $0.5 \mu \mathrm{l}$ upstream primer, $0.5 \mu \mathrm{l}$ down-

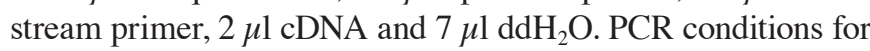
mouse COX-2 determination were: Initial denaturation at $95^{\circ} \mathrm{C}$ for $2 \mathrm{~min}$; 35 cycles of $94^{\circ} \mathrm{C}$ denaturation for $30 \mathrm{sec}$, annealing at $57^{\circ} \mathrm{C}$ for $30 \mathrm{sec}$ and elongation at $72^{\circ} \mathrm{C}$ for $30 \mathrm{sec}$; final elongation at $72^{\circ} \mathrm{C}$ for $4 \mathrm{~min}$ (iQ5; Bio-Rad Laboratories, Inc.). The $2^{-\Delta \Delta C q}$ method was used to calculate the relative expression of mRNA against $\beta$-actin. Each sample was tested in triplicate.

The expression of miR-381 was determined by miRcute miRNA RT-PCR kit (FP401; Tiangen), using U6 as internal reference. The sequences of human miR-381 were 5'-ACA CTCCAGCTGGGTATACAAGGGCAAGCT-3' (upstream) and 5'-TGGTGTCGTGGAGTCG-3' (downstream), and those of U6 were 5'-CTCGCTTCGGCAGCACA-3' (upstream) and 5'-AACGCTTCACGAATTTGCGT-3' (downstream). PCR reaction system $(20 \mu \mathrm{l})$ for human miR-381 determination was composed of $10 \mu 1$ RT-qPCR-Mix, $0.5 \mu 1$ upstream primer,

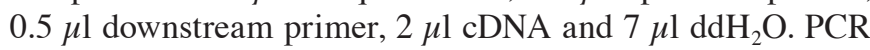
conditions for human miR-381 determination were: Initial denaturation at $95^{\circ} \mathrm{C}$ for $5 \mathrm{~min} ; 40$ cycles of $95^{\circ} \mathrm{C}$ denaturation for $15 \mathrm{sec}$, annealing at $60^{\circ} \mathrm{C}$ for $30 \mathrm{sec}$, and elongation at $72^{\circ} \mathrm{C}$ for $30 \mathrm{sec}$ (iQ5; Bio-Rad Laboratories, Inc.). The sequences of mouse miR-381 were 5'-ACGAGCGATACAAGGGCAAGC-3' (upstream) and 5'-GCGAGCACAGAATAAATACGACTC ACTA-3' (downstream), and those of U6 were 5'-CTCGCT TCGGCAGCACATATACT-3' (upstream) and 5'-ACGCTT CACGAATTTGCGTGTC-3' (downstream). PCR reaction system $(25 \mu \mathrm{l})$ for mouse miR-381 determination was composed of $12.5 \mu \mathrm{l} \mathrm{SYBR}$ Premix ExTaq ${ }^{\mathrm{TM}}, 0.5 \mu \mathrm{l}$ upstream primer, $0.5 \mu 1$ downstream primer, $1 \mu \mathrm{l}$ cDNA and $10.5 \mu \mathrm{l} \mathrm{ddH}_{2} \mathrm{O}$. PCR conditions for mouse miR-381 determination were: Initial denaturation at $95^{\circ} \mathrm{C}$ for $5 \mathrm{~min} ; 40$ cycles of $95^{\circ} \mathrm{C}$ denaturation for $10 \mathrm{sec}$, annealing at $60^{\circ} \mathrm{C}$ for $30 \mathrm{sec}$ and elongation at $72^{\circ} \mathrm{C}$ for $15 \mathrm{sec}$ (iQ5; Bio-Rad Laboratories, Inc.). The $2^{-\Delta \Delta C a}$ method was used to calculate the relative expression of miR-381 against U6. Each sample was tested in triplicate.

Enzyme-linked immunosorbent assay (ELISA). Serum were tested using human COX-2 ELISA kit (ab52237; Abcam, Cambridge, UK) and mouse COX-2 ELISA kit (YQ-16-3537K; Imunbio, Beijing, China). In microplates, standards (50 $\mu$ l), samples (10 $\mu 1$ sample liquid and $40 \mu 1$ diluent) and blank were set into predefined wells. In the wells for standards and samples, 
horseradish peroxidase-labelled conjugates $(100 \mu \mathrm{l})$ were added before sealing the plates for incubation at $37^{\circ} \mathrm{C}$ for $1 \mathrm{~h}$. After washing the plates for 5 times, substrates $\mathrm{A}(50 \mu \mathrm{l})$ and $\mathrm{B}(50 \mu \mathrm{l})$ were added into each well. After incubation at $37^{\circ} \mathrm{C}$ for $15 \mathrm{~min}$, stop solution $(50 \mu \mathrm{l})$ was added into each well, and absorbance of each well was measured at $450 \mathrm{~nm}$ within $15 \mathrm{~min}$.

Bioinformatics. Bioinformatics prediction is a powerful tool for the study of the functions of miRNAs. To understand the regulatory mechanism of COX-2 in VM, we used miRanda (http://www.microrna.org/microrna/home.do), TargetScan (http://www.targetscan.org), PiTa (http://genie .weizmann.ac.il/pubs/mir07/mir07_data.html), RNAhybrid (http://bibiserv.techfak.uni-bielefeld.de/rnahybrid/) and PICTA (http://pictar.mdc-berlin.de/) to predict miRNA molecules that might regulate COX-2, and found that miR-381 was able to potentially regulate COX-2 (Fig. 1).

Automatic biochemical analysis. The contents of creatine kinase (CK-MB) and lactate dehydrogenase (LDH) were determined according to relative kits (Beckman Coulter, Inc., Brea, CA, USA). Reagent I (250 $\mu \mathrm{l})$ was preincubated at $37^{\circ} \mathrm{C}$ in water bath for $3 \mathrm{~min}$, and then liquid samples $(10 \mu \mathrm{l})$ were mixed with reagent $\mathrm{I}(250 \mu \mathrm{l})$ before incubation at $37^{\circ} \mathrm{C}$ in water bath for $10 \mathrm{~min}$. Then, reagent II (50 $\mu \mathrm{l})$ was added. Within $5 \mathrm{~min}$, absorbance was measured continuously. Contents of CK-MB and LDH were determined by average absorbance increase rate. The results were automatically calculated and given by AU5800 automatic biochemical analyzer (Beckman Coulter, Inc.).

Western blotting. Precooled Radio-Immunoprecipitation Assay (RIPA) lysis buffer $(600 \mu \mathrm{l} ; 50 \mathrm{mM}$ Tris-base, $1 \mathrm{mM}$ EDTA, $150 \mathrm{mM} \mathrm{NaCl}, 0.1 \%$ sodium dodecyl sulfate, $1 \%$ Triton X-100, 1\% sodium deoxycholate (Beyotime Institute of Biotechnology, Shanghai, China) was used to lyse the samples. After lysis for $50 \mathrm{~min}$ on ice, the mixture was centrifuged at $12,000 \mathrm{x} \mathrm{g}$ at $4^{\circ} \mathrm{C}$ for $5 \mathrm{~min}$. The supernatant was used to determine protein concentration by bicinchoninic acid (BCA) protein concentration determination kit (RTP7102, Real-Times Biotechnology Co., Ltd., Beijing, China). Protein samples $(20 \mu \mathrm{g})$ were then mixed with sodium dodecyl sulfate loading buffer before denaturation in boiling water bath for $5 \mathrm{~min}$. Afterwards, the samples were subjected to $10 \%$ sodium dodecyl sulfate-polyacrylamide gel electrophoresis. The resolved proteins were transferred to polyvinylidene difluoride membranes on ice $(100 \mathrm{~V}, 2 \mathrm{~h})$ and blocked with $5 \%$ skimmed milk at room temperature for $1 \mathrm{~h}$. Then, the membranes were incubated with rabbit anti-mouse COX-2 polyclonal primary antibody (1:1,000; ab15191; Abcam) and rabbit anti-mouse $\beta$-actin primary antibody (1:5,000; ab8227; Abcam) at $4^{\circ} \mathrm{C}$ overnight. After extensive washing with phosphate-buffered saline with Tween-20 for 3 times of $15 \mathrm{~min}$, the membranes were incubated with goat anti-rabbit horseradish peroxidase-conjugated secondary antibody $(1: 3,000$; ab6721; Abcam) for $1 \mathrm{~h}$ at room temperature before washing with phosphate-buffered saline with Tween-20 for 3 times of $15 \mathrm{~min}$. Then, the membrane was developed with enhanced chemiluminescence detection kit (Abcam) for imaging. Image lab v3.0 software (Bio-Rad Laboratories, Inc.) was used to acquire and analyze imaging signals. The relative content of COX-2 protein was expressed as $\mathrm{COX}-2 / \beta$-actin ratio.

Dual luciferase reporter assay. According to bioinformatics results, wild-type (WT) and mutant seed regions of miR-381 in the 3'-UTR of COX-2 gene were chemically synthesized in vitro, added with Spe-1 and HindIII restriction sites, and then cloned into pMIR-REPORT luciferase reporter plasmids. Plasmids $(0.8 \mu \mathrm{g})$ with WT or mutant 3'-UTR DNA sequences were co-transfected with agomiR-381 (100 nM; Sangon Biotech, Shanghai, China) into 293 T cells. After cultivation for $24 \mathrm{~h}$, the cells were lysed using dual luciferase reporter assay kit (Promega Corporation, Madison, WI, USA) according to the manufacturer's manual, and fluorescence intensity was measured using GloMax 20/20 luminometer (Promega Corporation). Using renilla fluorescence activity as internal reference, the fluorescence values of each group of cells were measured.

Statistical analysis. The results were analyzed using SPSS 18.0 statistical software (IBM Corp., Armonk, NY, USA). The data were expressed as means \pm standard deviations. Data were tested for normality. Multigroup measurement data were analyzed using one-way ANOVA. In case of homogeneity of variance, Least Significant Difference and Student-Newman-Keuls methods were used; in case of heterogeneity of variance, Tamhane's T2 or Dunnett's T3 method was used. P<0.05 was considered to indicate a statistically significant difference.

\section{Results}

Children with VM have higher COX-2 levels in peripheral blood than those who have recovered from VM. To measure the expression of COX-2 mRNA and protein in serum, RT-qPCR and ELISA were carried out. The data showed that the expression of COX-2 mRNA and protein in serum from children with VM were significantly higher than those in control group, respectively $(\mathrm{P}<0.05$; Fig. $2 \mathrm{~A}$ and $\mathrm{B})$. The result suggests that children with VM have higher COX-2 levels in peripheral blood than those who have recovered from VM.

Children with VM have lower miR-381 levels in peripheral blood than those who have recovered from VM. To investigate the level of miR-381 in peripheral blood, RT-qPCR was employed. The data showed that expression of miR-381 in serum from children with VM were significantly lower than those from control group $(\mathrm{P}<0.05$; Fig. 3). The result indicates that children with VM have lower miR-381 levels in peripheral blood than those who have recovered from VM.

CVB3 infection results in damages in myocardium of mice, and elevates $C K-M B$ and $L D H$ contents. To determine the contents of CK-MB and $\mathrm{LDH}$, automatic biochemical analysis was performed. The data showed that the concentrations of CK-MB and LDH in peripheral blood from mice infected by CVB3 were significantly higher than those from mice in control group, respectively ( $\mathrm{P}<0.05$; Fig. $4 \mathrm{~A}$ and $\mathrm{B})$. The result suggests that CVB3 infection results in damages in myocardium of mice, and elevates CK-MB and LDH contents. 
A $3^{\prime}$ ugUCUCUCGAACGGGAACAUAu $5^{\prime}$ hsa-miR-381

$$
\text { || | : || |||||| }
$$

2316:5' auAGUCAAUAUG--CUUGUAUa 3' PTGS2

B 3' ugucUCUCGAACGGGACAUAu 5' mmu-miR-381

$$
\text { |I ||| |||||||| }
$$

\section{7:5' aaucAGACCUU--CCUUGUAUg 3' Ptgs2}

Figure 1. Direct interaction between microRNA-381 and cyclooxygenase (COX)-2 in (A) human and (B) mouse. Bioinformatics prediction is a powerful tool for the study of the functions of miRNAs. To understand the regulatory mechanism of COX-2, we used miRanda (http://www.microrna .org/microrna/home.do), TargetScan (http://www.targetscan.org), PiTa (http://genie.weizmann.ac.il/pubs/mir07/mir07_data.html), RNAhybrid (http://bibiserv.techfak.uni-bielefeld.de/rnahybrid/) and PICTA (http://pictar .mdc-berlin.de/) to predict miRNA molecules that might regulate COX-2, and found that miR-381 was able to potentially regulate COX-2.
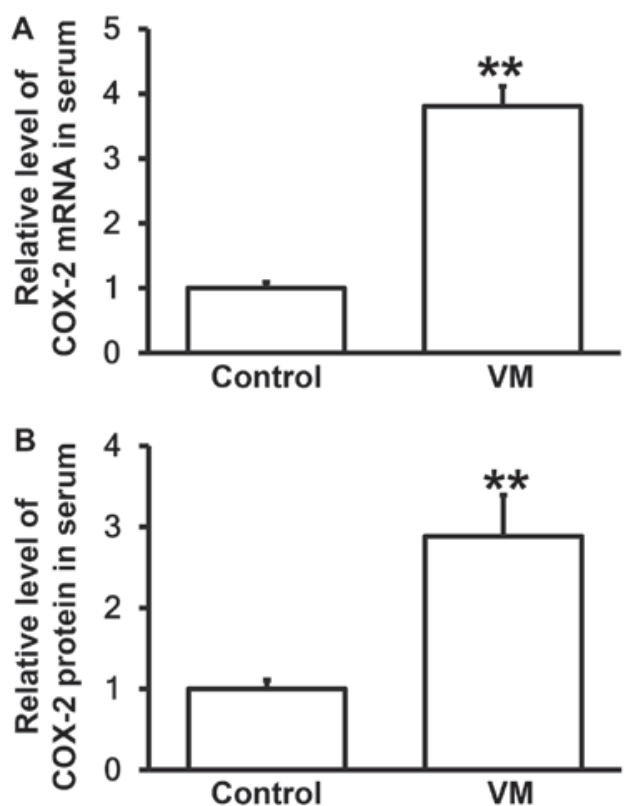

Figure 2. Expression of COX-2 (A) mRNA and (B) protein in serum from children. Children who have recovered from viral myocarditis (VM) were included into control group and those with VM were included into VM group. RT-qPCR was used to measure the expression of mRNA in serum, while ELISA was used to determine protein contents in serum. ${ }^{* *} \mathrm{P}<0.01$ compared with control group.

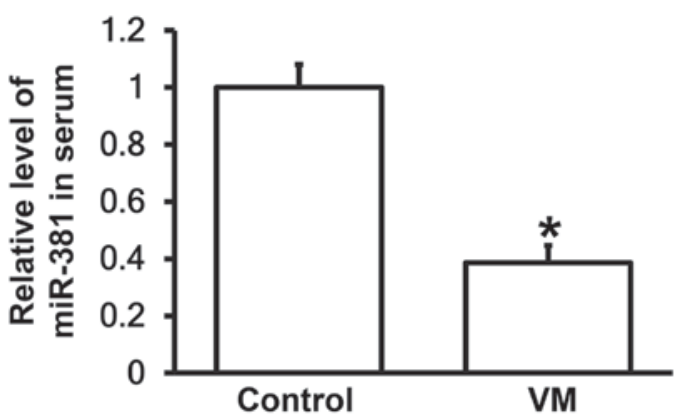

Figure 3. Expression of miR-381 in serum from children. Children who have recovered from viral myocarditis (VM) were included into control group and those with VM were included into VM group. RT-qPCR was used to measure the expression of miR-381 in serum. ${ }^{*} \mathrm{P}<0.05$ compared with control group.
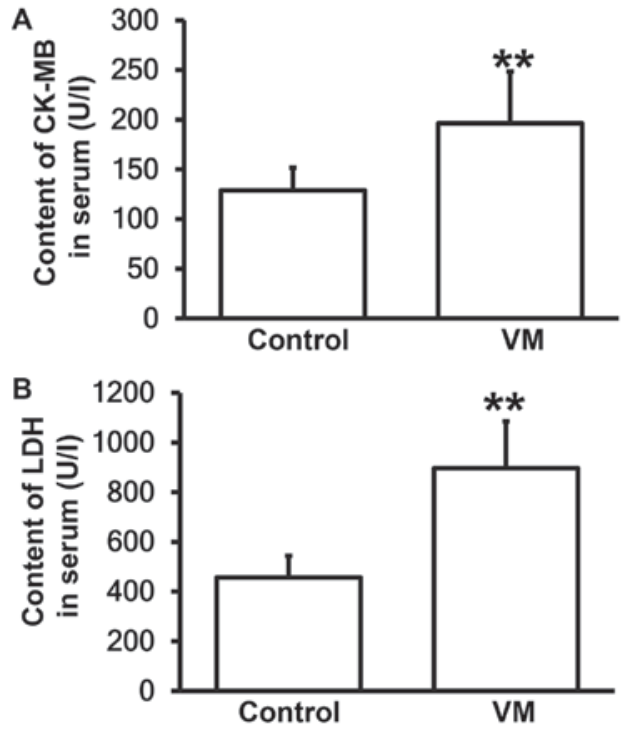

Figure 4. Contents of (A) creatine kinase (CK-MB) and (B) lactate dehydrogenase $(\mathrm{LDH})$ in serum from mice. Mice in control group $(n=30)$ were not infected by any virus and intraperitoneally injected with saline $(0.2 \mathrm{ml})$, while those in viral myocarditis (VM) group $(n=30)$ were intraperitoneally injected with 100 TCID50 CVB3 (0.2 ml; Biopike, Beijing, China), and one hour later, the mice were injected with saline $(0.2 \mathrm{ml})$. Contents of CK-MB and $\mathrm{LDH}$ were determined by automatic biochemical analysis. ${ }^{* *} \mathrm{P}<0.01$ compared with control.
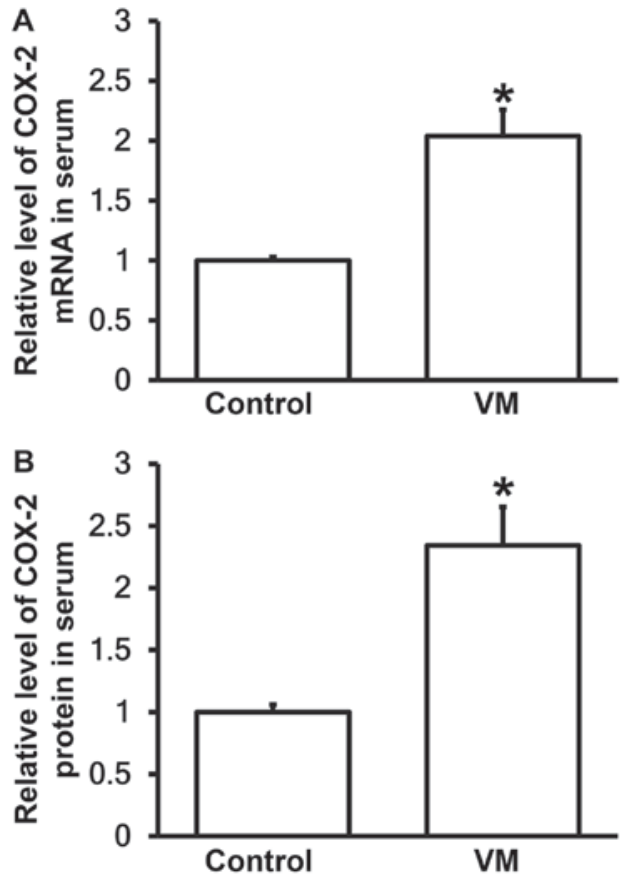

Figure 5. Expression of COX-2 (A) mRNA and (B) protein in serum from mice. Mice in control group $(n=30)$ were not infected by any virus and intraperitoneally injected with saline $(0.2 \mathrm{ml})$, while those in viral myocarditis (VM) group $(n=30)$ were intraperitoneally injected with 100 TCID50 CVB3 (0.2 ml; Biopike, Beijing, China), and one hour later, the mice were injected with saline $(0.2 \mathrm{ml})$. RT-qPCR was used to measure the expression of mRNA in serum, while ELISA was used to determine protein contents in serum. ${ }^{*} \mathrm{P}<0.05$ compared with control group.

VM model mice have increased COX-2 levels in peripheral blood than normal mice. To measure the expression of COX-2 mRNA and protein in serum, RT-qPCR and ELISA were 


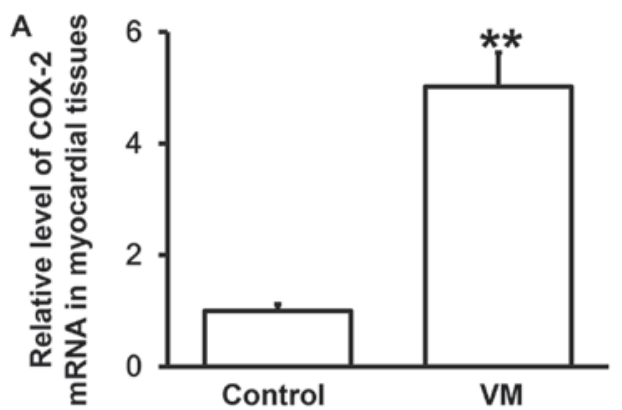

B Control VM
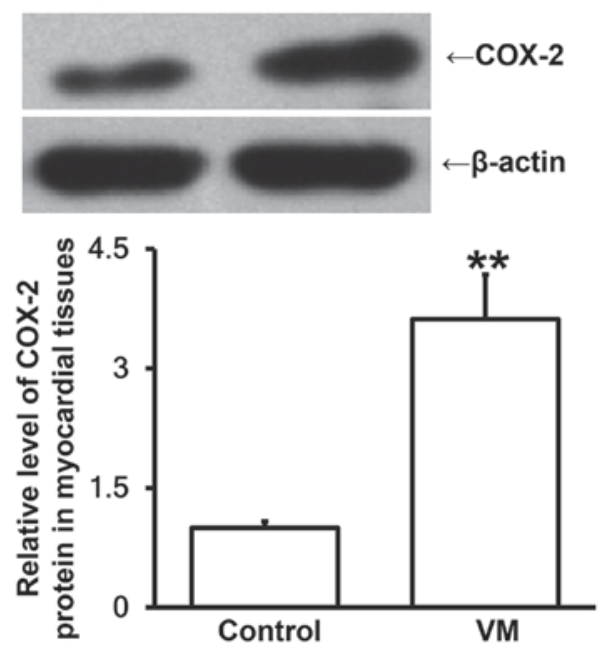

Figure 6. Expression of COX-2 (A) mRNA and (B) protein in myocardial tissues from mice. Mice in control group $(n=30)$ were not infected by any virus and intraperitoneally injected with saline $(0.2 \mathrm{ml})$, while those in viral myocarditis $(\mathrm{VM})$ group $(\mathrm{n}=30)$ were intraperitoneally injected with 100 TCID50 CVB3 (0.2 ml; Biopike, Beijing, China), and one hour later, the mice were injected with saline $(0.2 \mathrm{ml})$. RT-qPCR was used to measure the expression of mRNA, while Western blotting was used to determine protein expression. ${ }^{* * *} \mathrm{P}<0.01$ compared with control group.
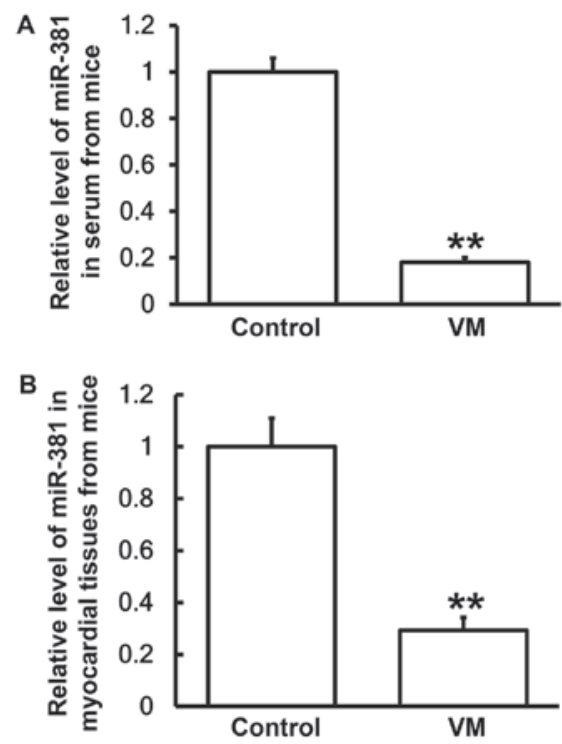

Figure 7. Expression of miR-381 (A) serum and (B) myocardial tissues from mice. Mice in control group $(\mathrm{n}=30)$ were not infected by any virus and intraperitoneally injected with saline $(0.2 \mathrm{ml})$, while those in viral myocarditis (VM) group $(n=30)$ were intraperitoneally injected with 100 TCID50 CVB3 (0.2 ml; Biopike, Beijing, China), and one hour later, the mice were injected with saline $(0.2 \mathrm{ml})$. RT-qPCR was used to measure the expression of miR-381 in both samples. ${ }^{* *} \mathrm{P}<0.01$ compared with control group.
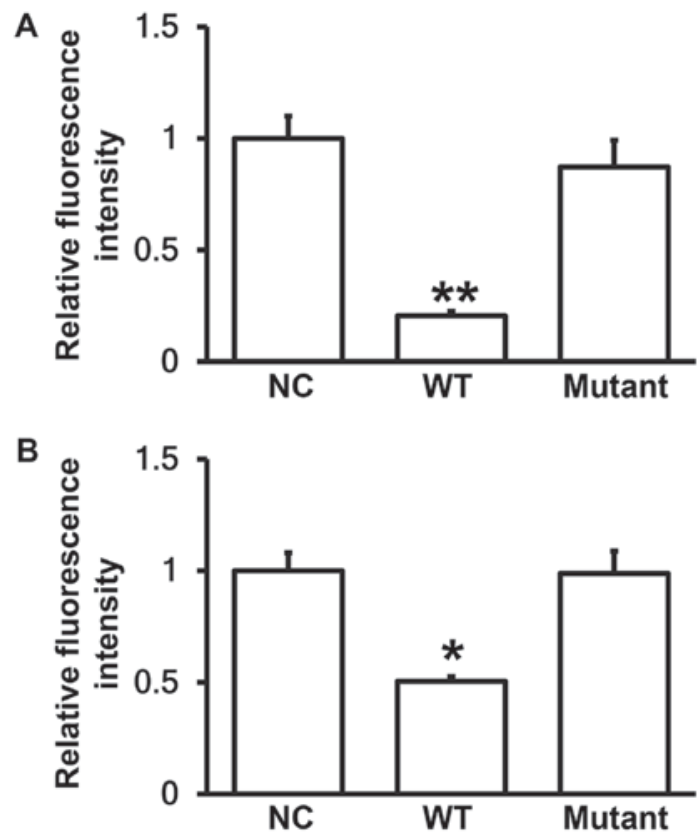

Figure 8. Identification of interaction between (A) human and (B) mouse miR-381 and COX-2 using dual luciferase reporter assay. Plasmids $(0.8 \mu \mathrm{g})$ with wild-type (WT) or mutant 3'-UTR DNA sequences were co-transfected with miR-381 mimics into 293T cells. After cultivation for $24 \mathrm{~h}$, the cells were lysed using dual luciferase reporter assay kit (Promega Corporation, Madison, WI, USA), and fluorescence intensity was measured using GloMax 20/20 luminometer (Promega Corporation). Using renilla fluorescence activity as internal reference, the fluorescence values of each group of cells were measured. " $\mathrm{P}<0.05$ and ${ }^{* * *} \mathrm{P}<0.01$ compared with negative control (NC) group.

carried out. The data showed that the levels of COX-2 mRNA and protein in serum from VM model mice were significantly higher than those in control group, respectively $(\mathrm{P}<0.05$; Fig. 5A and B). The result suggests that VM model mice have increased COX-2 levels in peripheral blood than normal mice.

$V M$ model mice have elevated COX-2 expression in myocardial tissues than normal mice. To measure the levels of COX-2 mRNA and protein in myocardial tissues, RT-qPCR and Western blotting were employed. The data showed that the levels of COX-2 mRNA and protein in myocardial tissues from VM model mice were significantly higher than those in control group, respectively $(\mathrm{P}<0.05$; Fig. 6A and $\mathrm{B})$. The result indicates that VM model mice have elevated COX-2 expression in myocardial tissues than normal mice.

$V M$ model mice have lower miR-381 levels in peripheral blood and myocardial tissues than normal mice. To determine the expression of miR-381 in peripheral blood and myocardial tissues from mice, RT-qPCR was used. The data showed that expression of miR-381 in serum and myocardial tissues from VM model mice were significantly reduced than those from normal mice, respectively ( $\mathrm{P}<0.05 ;$ Fig. $7 \mathrm{~A}$ and $\mathrm{B})$. The result suggests that VM model mice have lower miR-381 levels in peripheral blood and myocardial tissues than normal mice.

miR-381 can bind with the 3'-UTR seed regions of both human and mouse COX-2 mRNA to regulate their expression. To identify the interaction between miR-381 and the 3'-UTR of 
human and mouse COX-2 mRNA, dual luciferase reporter assay was performed. The fluorescence value of cells co-transfected with miR-381 mimics and pMIR-REPORT-WT luciferase reporter plasmids was significantly lower than that in negative control group $(\mathrm{P}<0.05)$. By contrast, the fluorescence value of cells co-transfected with miR-381 mimics and pMIR-REPORT-mutant luciferase reporter plasmids was not significantly different from that in negative control group ( $\mathrm{P}>0.05$; Fig. 8A and B). The result indicates that miR-381 can bind with the 3'-UTR seed regions of both human and mouse COX-2 mRNA to regulate their expression.

\section{Discussion}

VM is a clinically common disease in children. It is reported that the incidence of VM in children is increasing (11). Because the clinical manifestations of VM are atypical, the prognosis of the children is seriously affected if the diagnosis and treatment are not timely (11). The pathological changes of myocardial cells are the main pathological changes in VM, and they include direct damages to cardiac muscle cells by virus and immune damages (12). Patients with persistent VM have poor prognosis, with an average 5-year survival rate of about $50 \%$. Persistent chronic inflammation can lead to myocardial cell necrosis, myocardial hypertrophy and cell apoptosis, which can lead to myocardial fibrosis, dilated cardiomyopathy (DCM) and heart failure (13).

In the present study, we have first detected the related indexes in peripheral blood from children with VM, and then constructed mouse model of VM by infecting the mice with CVB3. CVB3 can cause extensive damages to myocardium in weaning and adult animals (14), leading to similar progression and pathological changes of the disease (15). Our results on the peripheral blood of children with VM show that expression of COX-2 in peripheral blood is significantly up-regulated, suggesting that inflammatory responses exist in VM. Similar results have also been observed in our mouse model. The expression of CK-MB and $\mathrm{LDH}$ in the blood of the mice with pathological myocarditis is significantly up-regulated, suggesting the occurrence of myocardial injury. In addition, COX-2 expression in peripheral blood and myocardial tissues from the mice is also up-regulated, further suggesting that COX-2 plays a role in VM.

miRNA is an important class of posttranscriptional regulator. It is reported that miRNA is widely involved in the regulation of cardiac development, cardiac hypertrophy, heart failure, and vascular proliferation (16). For example, Wang et al report that miR-142-3p inhibits myocardial cell injury induced by hypoxia/reoxygenation by targeting high mobility group box 1 gene (17). Singh et al discover that miR-200c affects MAPK signaling pathway and promotes cardiomyocyte hypertrophy by targeting DUSP-1 gene expression (18). Our bioinformatics prediction shows that miRNA-381 is closely related with COX-2, and may be an upstream miRNA that regulates COX-2. Intracellular, small, non-coding miRNAs may cut mRNA of COX-2 and inhibit its translation (19). miRNAs exert regulatory actions in a way of cutting, and promote the up-regulation or down-regulation of mRNA expression to mediate the regulation of protein-coding genes, playing important roles in the occurrence and development of diseases $(20,21)$. It is discovered that down-regulation of miR-381 in colon cancer tissues leads to up-regulation of LRH-1 and induces proliferation and invasion of colon cancer cells (22). In addition, miR-381, which is present in the p53/PTTG1 negative feedback loop, can inhibit the growth of pituitary adenomas (23). miR-381 is closely related to MDR1 gene and plays an important role in multidrug resistance (24). Together with miR-424, miR-381 can target WEE1 gene to inhibit the activity of renal cancer Cdc2 cells (25). Moreover, miR-381 is closely related to lung adenocarcinoma (26). These studies demonstrate that miR-381 is closely related to the occurrence and development of human diseases. Our data show that miR-381 expression is reduced in peripheral blood of children with VM. Considering the abnormally high expression of COX-2 in the blood of these children, we hypothesize that down-regulation of miR-381 is a reason for the up-regulation of COX-2. Consistently, we have observed similar trends in peripheral blood and myocardial tissues from VM model mice. Our observation further demonstrates that negative regulatory relationship exists between miR-381 and COX-2 in various species. Lastly, we have identified that miR-381 directly binds with the 3 '-UTR of COX-2 mRNA, and regulates its expression.

In conclusion, the present study demonstrates that miR-381 expression in peripheral blood is decreased in children with VM, being negatively correlated with COX-2 expression. In addition, miR-381 alleviates myocardial cell injury by inhibiting myocardial cell inflammatory responses via the regulation of COX-2. Therefore, miR-381 may be a potential diagnostic and therapeutic biomarker for VM in children.

\section{Acknowledgements}

We would like to thank Dr Shuzhen Deng from Wuhan Children's Hospital.

\section{References}

1. Wang C, Dong C and Xiong S: IL-33 enhances macrophage M2 polarization and protects mice from CVB3-induced viral myocarditis. J Mol Cell Cardiol 103: 22-30, 2017.

2. Nguyen VK, Klawonn F, Mikolajczyk R and Hernandez-Vargas EA: Analysis of practical identifiability of a viral infection model. PLoS One 11: e0167568, 2016.

3. Rienks M, Papageorgiou A, Wouters K, Verhesen W, Leeuwen RV, Carai P, Summer G, Westermann D and Heymans S: A novel 72-kDa leukocyte-derived osteoglycin enhances the activation of toll-like receptor 4 and exacerbates cardiac inflammation during viral myocarditis. Cell Mol Life Sci 74: 1511-1525, 2017.

4. Yue-Chun L, Guang-Yi C, Li-Sha G, Chao X, Xinqiao T, Cong L, Xiao-Ya D and Xiangjun Y: The protective effects of ivabradine in preventing progression from viral myocarditis to dilated cardiomyopathy. Front Pharmacol 7: 408, 2016.

5. Márquez-González H, López-Gallegos D, González-Espinosa AM, Zamudio-López JO and Yáñez-Gutiérrez L: Effect of immune therapy in the prognosis of viral myocarditis in pediatric patients. Rev Med Inst Mex Seguro Soc 54 (Suppl 3): S296-S301, 2016.

6. Yu M, Long Q, Li HH, Liang W, Liao YH, Yuan J and Cheng X: IL-9 inhibits viral replication in coxsackievirus B3-induced myocarditis. Front Immunol 7: 409, 2016.

7. An B, Liu X, Li G and Yuan H: Interleukin-37 ameliorates coxsackievirus B3-induced viral myocarditis by modulating the Th17/regulatory $\mathrm{T}$ cell immune response. J Cardiovasc Pharmacol 69: 305-313, 2017. 
8. Alhouayek M and Muccioli GG: COX-2-derived endocannabinoid metabolites as novel inflammatory mediators. Trends Pharmacol Sci 35: 284-292, 2014.

9. Hao Y, Gu X, Zhao Y, Greene S, Sha W, Smoot DT, Califano J, Wu TC and Pang X: Enforced expression of miR-101 inhibits prostate cancer cell growth by modulating the COX-2 pathway in vivo. Cancer Prev Res (Phila) 4: 1073-1083, 2011.

10. Wu T: Diagnostic criteria for viral myocarditis (Revised Draft). Chin J Prac Pediat 5: 315, 2000 (In Chinese).

11. Casadonte JR, Mazwi ML, Gambetta KE, Palac HL, McBride ME, Eltayeb OM, Monge MC, Backer CL and Costello JM: Risk factors for cardiac arrest or mechanical circulatory support in children with fulminant myocarditis. Pediatr Cardiol 38: 128-134, 2017.

12. Simpson KE, Storch GA, Lee CK, Ward KE, Danon S, Simon CM, Delaney JW, Tong A and Canter CE: High frequency of detection by pcr of viral nucleic acid in the blood of infants presenting with clinical myocarditis. Pediatr Cardiol 37: 399-404, 2016.

13. Tse G, Yeo JM, Chan YW, Lai ET and Yan BP: What is the arrhythmic substrate in viral myocarditis? Insights from clinical and animal studies. Front Physiol 7: 308, 2016.

14. Grodums EI and Dempster G: The pathogenesis of Coxsackie group B viruses in experimental infection. Can J Microbiol 8 : 105-113, 1962

15. Webb SR, Loria RM, Madge GE and Kibrick S: Susceptibility of mice to group B coxsackie virus is influenced by the diabetic gene. J Exp Med 143: 1239-1248, 1976.

16. Bardooli F, McAlindon E, Littlejohns B, Suleiman MS, Chiara BD and Baumbach A: TCT-184 Early changes in circulating miRNA 133a are indicative of cardiac remodelling after 3 months in patients presenting with acute ST elevation myocardial infarction. J Am Coll Cardiol 68: B75-B76, 2016.

17. Wang Y, Ouyang M, Wang Q and Jian Z: MicroRNA-142-3p inhibits hypoxia/reoxygenationinduced apoptosis and fibrosis of cardiomyocytes by targeting high mobility group box 1 . Int J Mol Med 38: 1377-1386, 2016.

18. Singh GB, Raut SK, Khanna S, Kumar A, Sharma S, Prasad R and Khullar M: MicroRNA-200c modulates DUSP-1 expression in diabetes-induced cardiac hypertrophy. Mol Cell Biochem 424: $1-11,2017$.
19. Liu D, Wang D, Xu Z, Gao J, Liu M, Liu Y, Jiang M and Zheng D: Dysregulated expression of miR-101b and miR-26b lead to age-associated increase in LPS-induced COX-2 expression in murine macrophage. Age (Dordr) 37: 97, 2015.

20. Chen K and Rajewsky N: The evolution of gene regulation by transcription factors and microRNAs. Nat Rev Genet 8: 93-103, 2007.

21. Lewis BP, Burge CB and Bartel DP: Conserved seed pairing, often flanked by adenosines, indicates that thousands of human genes are microRNA targets. Cell 120: 15-20, 2005.

22. Liang Y, Zhao Q, Fan L, Zhang Z, Tan B, Liu Y and Li Y: Down-regulation of MicroRNA-381 promotes cell proliferation and invasion in colon cancer through up-regulation of LRH-1. Biomed Pharmacother 75: 137-141, 2015.

23. Liang HQ, Wang RJ, Diao CF, Li JW, Su JL and Zhang S: The PTTG1-targeting miRNAs miR-329, miR-300, miR-381 and miR-655 inhibit pituitary tumor cell tumorigenesis and are involved in a p53/PTTG1 regulation feedback loop. Oncotarget 6: 29413-29427, 2015.

24. Xu Y, Ohms SJ, Li Z, Wang Q, Gong G, Hu Y, Mao Z, Shannon MF and Fan JY: Changes in the expression of miR-381 and miR-495 are inversely associated with the expression of the MDR1 gene and development of multi-drug resistance. PLoS One 8: e82062, 2013.

25. Chen B, Duan L, Yin G, Tan J and Jiang X: Simultaneously expressed miR-424 and miR-381 synergistically suppress the proliferation and survival of renal cancer cells-Cdc2 activity is up-regulated by targeting WEE1. Clinics (Sao Paulo) 68: 825-833, 2013.

26. Rothschild SI, Tschan MP, Jaggi R, Fey MF, Gugger M and Gautschi O: MicroRNA-381 represses ID1 and is deregulated in lung adenocarcinoma. J Thorac Oncol 7: 1069-1077, 2012. 